\title{
A Context-sensitive Approach to Analysing Talk in Strategy Meetings
}

\author{
Ian Clarke, Winston Kwon ${ }^{1}$ and Ruth Wodak ${ }^{2}$ \\ Newcastle University Business School, Citywall, Citygate, St James Boulevard, Newcastle-upon-Tyne NE1 \\ $4 \mathrm{JH}, \mathrm{UK},{ }^{1}$ Centre for Strategic Management, Lancaster University Management School, Lancaster LA1 \\ $4 Y X$, UK, and ${ }^{2}$ Department of Linguistics and English Language, Lancaster University, Lancaster \\ LA1 4YL, UK \\ Corresponding author email: i.clarke@newcastle.ac.uk
}

\begin{abstract}
The talk of managers in meetings is central to organizational life and crucial to research in strategic management, as well as managerial and organizational cognition, sensemaking and decision-making. To achieve full understanding, both the text and the context of discussion require systematic analysis, but most approaches treat context as everything that is known and observed beyond the immediate text. This obscures different readings of the text of meetings. To resolve this problem, the discourse historical approach (DHA) to critical discourse analysis is outlined as a framework within which researchers can analyse the text and context of talk in meetings. The primary contribution of this paper is to isolate four 'levels of context' as a heuristic framework within which discursive practices, strategies and texts can be located. By making explicit the levels of contextual analysis that are implicit in other methods, and illustrating the DHA using an episode of strategic discussion from a multinational company, this paper shows how researchers can use the approach to analyse the naturally occurring talk of senior managers in meetings, which is arguably the most important but yet under-explored venue for strategizing.
\end{abstract}

\section{Introduction}

Bradley: I'm at the same place as you, that probably the only difference I'd make to that I'd say, we've got what we've got today at Aberdeen, we'd better cater for that at Aberdeen Hills and we'd better look to grow additional manpower wherever we can in Melbourne and Sydney - [murmurs of assent] - So build the fucking building [laughter].

Mike:- which is where I've been for the past three or four years [more laughter] - Harris keeps trying to

The authors are grateful to the two anonymous reviewers of our paper, and the comments of the Associate Editor, Cathy Cassells, as well as the financial support of the UK ESRC/EPSRC Advanced Institute of Management Research (AIM) in the preparation of this manuscript, under grant number RES-331-25-0017 (Clarke). The authors would also like to thank Professors Julia Balogun and Gerry Johnson for their comments on an earlier draft of this paper. talk me out of it - I just keep saying I don't believe them.

For participants in the meeting to make sense of the above fragment, and for us as researchers, in addition to understanding English grammar and usage, we need to know more about the context of this discussion. For example, what do Bradley and Mike mean by 'place'? Here, place is not a location, but a metaphor for the discussants' position on the issue of whether or not to expand the corporate headquarters with a new building. As researchers, how do we know that this particular issue is of strategic significance to the organization, and therefore deserving of analytical attention? The organization is growing rapidly and facing competition from other industries in the domestic labour market for skilled engineers, so failure to meet this need is likely to result in delayed completion of projects and major financial losses. So why, when 
Bradley uses an expletive to refer to the 'building', do others laugh? To comprehend this, we need to know that the discussion is between senior directors of a multinational company who are familiar with each other, based in Australia, where there is an informal culture in which the use of expletives and slang are relatively acceptable forms of speech in organizational meetings. Is there is any significance in Harris trying to talk Mike 'out of it'? For this, we need to know that Mike is the Chief Executive, Bradley is the Chief Operating Officer, and Harris is the Finance Director whose 'buy-in' is crucial in an organization where there is a strong financial culture of governance in the company. Thus, there is tension in the meeting relating to whether to assess the need for a new building based on explicit and conservative budget estimates, or a more intuitive and holistic understanding of market trends.

What this brief illustration shows is that, in order to understand, analyse and explain a fragment of conversation, we need not only knowledge of a few facts surrounding the broad context of an event, but also to be able to draw upon and articulate knowledge of the event and its context in a systematic manner. This important point has been made by Keenoy and Oswick (2003), who note that:

the 'doing' of discourse analysis requires us to attend to aspects of bounded space and multiple locales - the landscapes within which discourse is conducted ... this process involves a robust delineation of text and context where the focal discourse is uncoupled and investigated independently of the physical surroundings and the wider social context in which it occurs ... these contexts (that is, other spaces) are not simply a backdrop to text, they are actually embedded within it: the text actually forms part of the context and vice versa. (pp. 139-140)

How then, do researchers as observers of such events reach this level of understanding? Obviously, participants are able do this tacitly and in real time, because they are familiar with each other's roles, they know each other, and will normally have prepared themselves to discuss what is on the meeting agenda. For organizational researchers outside the participants' social world, however, achieving this level of understanding is more difficult, and represents an important methodological challenge. How do we make sense of, in a non-intuitive but explicit, transparent and retroductable way, how strategists and other key organizational actors discuss, debate and ultimately make decisions on issues of strategic importance?

In order to answer this question, we outline in this paper the discourse historical approach (DHA) to critical discourse analysis (CDA), a key feature of which is a four-stage approach to the simultaneous analysis of text and context, with the latter being unpacked into four 'levels of context' (Wodak, 2001). We draw on the full text of an episode of discussion - the episode within which the utterances at the opening of this paper were embedded - in order to demonstrate how the DHA works. We show how these utterances between Bradley, Mike and others, who are arguing about the 'pros and cons' of the need to build a new production building in a multinational corporation, can be better understood through a systematic analysis of the text and context of the discussion. Stage 1 involves identifying a social issue of relevance to organization studies, which in our case concerned how language is used to shape ideas and persuade other actors involved in the decision-making process. Stage 2 requires the collection of data pertinent to answering this question: in our case, recorded transcripts of senior executive meetings over a number of months, plus interviews with each team member, collection of company documents used in the meetings, and our own notes from our observations of the meetings as they took place. These sources are important to help the analyst to make sense of the three levels of context beyond the immediate text, which is a unique feature of the DHA. Stage 3 involves the researchers being selective about the data they employ in order to narrow down the research question. For example, we used our own observations of a discourse facing the management team in our organization (over recruitment and retention of personnel) to narrow down to a question about how individuals present ideas in meetings to influence decisions, and how this is affected by the wider context in which they operate. In this stage, the researcher is encouraged to use pilot studies of episodes of data - such as the one used in this paper - to test assumptions and develop constructs and hypotheses. Stage 4 then uses the insights from the pilot to construct a critique of the theoretical issue under investigation, which is then investigated through recursive analysis of successive episodes in order to build theory retroduc- 
tively. The paper outlines in detail the four stages and four context 'levels' which characterize the DHA to CDA, and illustrates them with reference to a single episode of discussion.

This question of how to analyse how strategists influence discourse, by investigating the context as well as the text of their discussions, is particularly pertinent to the field of strategy, where there have been consistent calls to examine how organizational actors interact in the process of organizing (Cooren, 2007) to do the actual work of strategy (Jarzabkowski and Spee, 2009; Jarzabkowski, Balogun and Seidl, 2007; Johnson, Melin and Whittington, 2003; Whittington, 1996). In response to this call, there has been a growing emphasis on discourse analysis to examine the organizational practice of strategizing (Laine and Vaara, 2007). Despite this linguistic turn, however, there has been a tendency for most empirical studies to focus on secondary sources of data such as newspaper articles, interviews and company documents (e.g. Hellgren et al., 2002; Heracleous and Barrett, 2001; Knights and Morgan, 1995). Arguably, however, the simultaneous empirical engagement with both naturally occurring local talk and also more distant indirect texts remains an ideal yet elusive basis for the study of managers engaged in the discussion of strategic issues (Heracleous and Jacobs, 2008; Mantere and Vaara, 2008).

Despite meetings being conspicuous events in the strategy-making process and often being turned to during critical strategic incidents (Jarzabkowski and Seidl, 2008), empirical studies that focus on the role of meetings as a venue for strategizing are relatively few. A primary challenge facing researchers in attempting to study strategy meetings is dealing with the sheer quantity of data that can be captured from such an empirical event. The few empirical studies that focus on strategy meetings deal with this challenge by distilling the data through either a macro- or a micro-level lens. Macro-level analyses tend to abstract the content of meetings to an examination of patterns of activity (e.g. Jarzabkowski and Seidl, 2008; Maitlis, 2005) that fail to analytically engage with the actual content of what senior managers say or do. Micro-level analyses tend to rely on the lens of personal experience as meeting facilitators (e.g. Hodgkinson and Wright, 2002), artefacts produced during the discussion (e.g. Heracleous and Jacobs, 2008) or interviews with meeting participants (e.g. Johnson et al., 2010), which forces the researcher to rely overly on the interpretations of specific individuals to make sense of what actually happened in the meeting.

Thus, a weakness of the methodologies underlying these empirical studies is the inability to connect the actual practices of organizational actors (i.e. specifically what was said and done, and by whom) to broader organizational outcomes (i.e. implications for the strategic direction of the organization) and extra-organizational influences (i.e. the linkages between the practices of organizational actors and their professional, institutional or industry practices). Put simply, without a consideration of what such actors 'bring to the table' from the larger context, the description and interpretation of their discourse is incomplete and meaningless (see Stohl, 2007). It has therefore been strongly argued that it is precisely this problem that must be overcome in order to move the field of strategy research forward (Jarzabkowski, Balogun and Seidl, 2007; Johnson, Melin and Whittington, 2003; Whittington, 2006). We contend that at the heart of this problem is a methodological challenge with three elements: how do we bring together (a) contextual knowledge gained from analysis of secondary sources, and (b) direct observation of managers engaged in discussion of strategic issues via an in depth systematic analysis, in order to (c) assess their impact on broader outcomes, such as strategic organizational direction?

In response to this need, we adapt and develop a particular approach to CDA, the DHA, to create a rigorous methodological framework for researchers analysing the context as well as the talk of strategy meetings. We do this in three stages. First, we briefly examine two key perspectives on context taken from CDA to synthesize a new context-sensitive methodology for the analysis of naturally occurring talk. Second, we illustrate how this methodology can be applied using an excerpt of discussion from a meeting of a board of directors of a multinational company. Finally, we conclude by discussing how the approach can benefit strategic management researchers and practitioners.

\section{Towards a critical context-sensitive approach to the analysis of meetings}

All forms of CDA have roots in a synthesis of influences, including rhetoric, text linguistics, 
anthropology, philosophy, socio-psychology, cognitive science, literary studies and sociolinguistics, as well as applied linguistics and pragmatics (Wodak and Meyer, 2009). They have at least seven dimensions in common (Van Dijk, 2008; Wodak, 2008, 2011): an interest in naturally occurring language; a focus on larger units of analysis other than words and sentences (e.g. texts, discourses, conversations and speech acts); an extension of linguistics beyond sentence grammar to encompass action and interaction; extension to non-verbal interactions; a focus on the dynamics of interaction over time; an interest in the role of context on language use; and analysis of the phenomenon or concepts of text grammar and language use (e.g. topics, turntaking, argumentation, rhetoric, pragmatics, mental models). In order to address complex social problems, all forms of CDA are also inherently problem-oriented and interdisciplinary.

There is a misconception that the term 'critical' in CDA implies criticism or negativity (Chilton, 2010), rather than, as is the case, being rooted in 'critical theory' and oriented towards critiquing, challenging and possibly changing society. Rather, the aim of CDA is to take nothing for granted and open up all kinds of meaning productions to multiple readings. Furthermore, selfreflection of the researchers is continuously expected (Chilton et al., 2010; Reisigl and Wodak, 2001). Viewed through CDA, therefore, an organizational process - such as the making of a decision in a meeting - would beg the question not only how and why a particular decision was reached, but also what might have been done to produce a different outcome.

Recently, Van Dijk (2008) put forward a radical new theory of discursive context as a construct that exists within the heads of participants. This critical, socio-cognitive theory of 'context models' has three principal components. First, context models are based on experience and hierarchically structured, effectively acting as a heuristic guide for the individual to make sense of a communicative situation. They are therefore implicit and presupposed, influencing talk and text in indirect ways. Second, they are shared by individuals within groups, thus allowing for the fast mutual interpretation of relevant aspects of unique events and the production and comprehension of discourse. Third, the genre of the communicative situation is frequently known in advance, allowing participants to make presuppositions and thus engage in the purposeful production of appropriate texts and talk.

Van Dijk's novel conceptualization of discourse context is helpful to management and organizational researchers because it fundamentally challenges the narrow focus of many studies on the immediate text. It also overcomes the simplistic and flawed assumption that separates out the factors that might influence discourse at the 'micro-level' and the 'macro-level'. However, as Van Dijk points out, because this context model is socio-cognitive, it cannot be directly observed. Hence, he proposes three methods to uncover the effects of this unobservable context model across different communicative situations: (1) the systematic comparison of cases; (2) controlled experiments; and (3) the observation of everyday situations. The problem he identifies, therefore, is not so much theoretical as methodological.

Several approaches to CDA can facilitate these methods, and each of them has strengths. However, while there has been significant development of CDA in organization studies (e.g. Phillips et al., 2008), there has been a tendency to play down the differences between these different approaches and see them effectively as one. Therefore, although all CDA approaches are 'critical', here we focus on outlining and developing one such approach - the discourse historical approach (or DHA) - because it provides a robust set of discourse constructs and a heuristic framework for analysing the important issue of contextual influences on talk in empirically systematic ways.

The DHA is different from other forms of $\mathrm{CDA}$ in that it enables analysis of the historical (i.e. intertextual) dimension of discursive actions by exploring the ways in which particular genres of discourse are subject to change through time, and also by integrating social theories to explain context. Following Foucault (1972), 'historical context' includes the history and sub-system of meetings and narratives in the organization as well as wider forces. Consequently, 'history' can involve studying how language use changes over shorter timescales, for example, during one meeting (over a certain amount of time) or over several meetings, as part of latent and manifest rules and norms that serve to rationalize, explain and make sense of organizational events (e.g Baker et al., 2008; Lalouschek, Menz and 
Wodak, 1990, Linde, 2008; Mumby and Clair, 1997).

But how do we adapt the DHA approach which has been previously developed and used within the empirical domain of political studies to analyse political institutions, identity politics and organizations such as schools, crisis intervention centres and hospitals (Reisigl and Wodak, 2001, 2009; Wodak, 1986, 1996)? Here, the approach has been used to analyse the drafting of policy documents (Wodak, 2000; Wodak and Weiss, 2003) and the daily lives of politicians (Wodak, 2011). How do we bring it into the domain of management research to address a range of questions pertinent to how the strategy process is influenced through the interaction of senior managers in strategy meetings? The challenge of adapting the DHA to strategy research is twofold. First, the DHA approach in its source domain is both a theoretical research question (i.e. how and why do social actors use discourse to create representations of themselves to get their views accepted?) and a methodology for systematically bridging the immediate language of actors and the broader discourses of the social contexts within which they reside. In short, the methodology needs to be disentangled from the discourse theoretical research question. Second, rather than investigating written drafts of authored documents or public speeches, forms of discourse that are more easily accessible to non-expert outsiders, the analytical focus of strategy meetings tend to be on the naturally occurring talk (cf. Potter and Wetherell, 1987) of teams of senior managers engaged in discussions over highly specific and commercially sensitive information. Thus, the contextual knowledge about the individual team members, the organization, and its industry, which is gained through ethnographic field research, is a necessary prerequisite for gaining substantive insight into the dynamics of a strategy meeting.

In the next section of this paper, we outline how we have accommodated/developed the DHA approach and demonstrate its use as a methodological tool that can offer researchers insight into how strategists actually 'do the work of strategy' through discourse (Whittington, 1996). The DHA does this by gauging how the local talk of senior managers in strategy meetings is constructed and affected by broader contextual imperatives, resulting in organizational outcomes.

\section{The conceptual 'scaffolding' of the DHA}

To outline the DHA and illustrate how it is applied, we use a short episode of discussion from a meeting of a senior management team in a multinational company which occurred during an 'awayday' of the Australian business unit of Defence Systems International (DSI), ${ }^{1}$ a UKbased multinational company operating in the aerospace sector. Table 1 details the meeting participants, who gathered to provide inputs into an annual 'Integrated Plan', and the verbatim transcript of this discussion is shown in Figure 1. The specific topic of the discussion concerned whether or not there was a need for a new building to accommodate the growth of the organization.

The DHA can be thought of as both conceptual 'scaffolding' for making sense of an organizational phenomenon as well as a methodological approach. In the case of the example of text we use, we are attempting to understand how a discussion and decision by a management team to build a new building was influenced by the actions of the meeting participants in the episode of discussion drawn from a single meeting. To make sense of this episode, we must understand how the various categories of empirical data are interrelated and how the motives of organizational actors are connected to what they say, and why. Figure 2 illustrates this relation between the conceptual scaffolding of DHA and its practical application as a methodology. Conceptually, we see the empirical event under investigation as a phenomenon which has discursive manifestations across four heuristic 'levels of context' (Wodak, 2011):

\begin{tabular}{ll} 
Table 1. The Board of Directors of DSI Australia \\
\hline Mike & CEO \\
Bradley & Chief Operating Officer (COO) \\
Harris & Director of Finance \\
Adam & Director of Human Resources \\
Larry & Director of Engineering \\
Greg & Director of Contracts and Procurement \\
Will & Director of the Osprey Programme \\
Charlie & Director of the Peregrine Programme \\
Ted & Director of Aircraft Maintenance \\
\hline
\end{tabular}

${ }^{1}$ Readers should note that DSI is a pseudonym to protect the identity of our research sites and respondents. In addition, all the names of individuals, places and projects in the organization have been altered for the same reason. 
1 Ted: We've taken that view on the IP (Integrated Plan), Falcon 2 Simulator Systems and there's a deterioration across that. The 3 Kestrel Project, from memory, they ramped down that, keeping

4 a full aircraft integration capability, but there is a deep mine in

5 respect to that, so... It's where that training element, what we're

6 forecasting is the decline. So what we're forecasting is..

7 Will: I think it's... so what we're doing is... we're doing...

8 looking at closing base businesses, and we're forecasting down

9 to project's end, rather than saying well, it's capability-based

10 business heading out there, in a training simulation

11 competency... That's the work that Dave and Sam have been

12 doing for me, I'm going to get Nick in there to start to bring that 13 up...

14 Mike: I don't mind looking at the capabilities... for the

15 purposes of the IP, you're going to have to deploy that

16 capability on projects, you're going to have to badge it against

17 projects at some point... [Will: That's what we're doing...] to

18 build up your IP, but from a capability point of view, from a

19 business point of view, we've got to be planning your facilities

20 at a higher level you know, than project by project.

21 Greg: [emphatically] You're never going to... you'll never get 22 at it that way.

23 Will: Yeah... don't... I'm not disagreeing with that...

24 Greg: If you follow trends in the workforce, and Harris you 25 correct me... is that the workforce has been growing, take out

26 the contracts like Norwich with about 80 people, take out Fligh

27 Simulation with about 100 people that went across. You'll see

28 the trend is the business grows... continually... think about the

29 options we're talking about. That'll have some implications...

30 you think about to get down to the finer detail of what's going

31 to happen with the Training Aids, in and out, what Singapore

32 could look like 'Grey Box'-wise etc., it almost sounds to me like

33 the IP numbers that you've said are fuzzy-like, its not really

34 fixed. I' $m$ in a place that says, have a look at the capabilities

35 side of it, you've got 800 people, you've got the people that

36 you've got today, you plan on that basis but there's... you do a

37 match against the programmes, perhaps label the capability but

38 by and large, you've got what you've got and it's going to

39 change by two or three, four hundred people is what we're

40 saying today.

41 Mike: There's a burden there behind you guys.

42 Bradley: I'm at the same place as you, that probably the 43 only difference l'd make to that I'd say, we've got what we've 44 got today at Aberdeen, we'd better cater for that at Aberdeen

45 Hills and we'd better look to grow additional manpower

46 wherever we can in Melbourne and Sydney... [murmurs of

47 assent] ... So build the fucking building... [laughter]

48 Mike: ... which is where I've been for the past three or four

49 years... [laughter] ... Harris keeps trying to talk me out of it...

50 just keep saying I don't believe them..

51 Harris: Well we, we obviously need to do some more scenarios 52 around this because this as I say at the moment is showing that 53 even on the probable scenario which includes the $10 \%$ of

54 additional labour across all projects, includes Singapore, that

55 we'd still have and let's just take 211 for convenience, 112

56 surplus space plus the potential for another 107 so that's 220

57 odd... based on this. Now the scenarios that we've also got in

58 the pack, the cost-based pack, we've looked at MMA, we

59 looked at Brunei... okay and obviously they... they're not in the

60 probable because I think you were..

61 Will: Well when I said I was dodgy about Singapore..

62 Harris: ... but you're also very dodgy about MMA
63 [several people talk at the same time]

64 Greg: ... so you've got $\$ 60$ million in five years and we're

65 going to drop 300 people in the same time frame. [Will: Very

66 simply.] I just think that that data...

67 Harris: ... well then... \$60 million is \$50 million and \$30

68 million of that increase is tasking that doesn't actually exist in

69 projects... it's flat there and that's assuming that inflation's

70 going at $3 \%$ per annum.

71 Greg: ... so we're going to drop to that... okay say we are at 72 where we are today. The business doesn't change in the next 73 five years, we're going to drop 300 people. I don't believe it.

74 Bradley: Neither do I. [Greg: I don't believe it.] Which 75 is why this is going to end up being a judgement. It's going to 76 end up..

77 Mike: What would be the quality of the accommodation if you 78 decided to... the other thing you've got is that Aberdeen Hills

79 site... we've got a whole bunch of people in the Evans Building,

80 we've got a bunch of people in sort of half decent

81 accommodations somewhere else, and then you start to

82 refurbish very old buildings... so we can move the people from

83 the north to the south...

84 Adam: You've got to consider the infrastructure that comes with

85 that, for example the small cafeteria that's used on the southern

86 side is apparently well utilised, so we're going to have to

87 increase perhaps the size of the cafeteria on the northern side so

88 there's extra cost, and there's potentially additional car parking

89 as well because we can't all park on the road, and the

90 additional car parks we have will not accommodate the 400 or

91 whatever it is on the southern site, so there's additional car

92 parking, cafeteria infrastructure type work as well that has to be

93 accommodated if we go for building B, and then if you to for

94 building B...

95 Charlie: Yeah but..

96 Adam: I think and my view is... sorry Charlie... to get out of

97 the leased buildings... the main ones, we've got those until

98 2008, so if these numbers are anywhere near correct, by the

99 time we get out of that by the end of 2008, according to these

100 plans, we don't have a surplus on the site.

101 Mike: Well we do, I mean we don't have the surplus.

102 Charlie: I don't believe it... you make your decision on

103 what it is

104 Adam: So here's the debate. You make the call now and say

105 we will, or do you go based on what Harris's doing and what

106 I've been part of which is try to bottom this up and find out

107 what actually... [several people speak at once] and then you

108 make the decision, are you going to build on Aberdeen Hills

109 and/or Outer Bay, or do you build in Melbourne and/or Sydney?

110 Bradley:I think, we've got what we've got. We've got people 111 spread all over the fucking place in really sub-standard operating 112 environments. We've got a huge challenge around the business

113 in terms of retention. We're not going to assist our cause on

114 retention at all without a half decent working environment that

115 facilitates communication on site, which you could say is

116 dysfunctional at the moment, so if you take the decision that

117 you're a sustainable business, which I don't think any of us

118 doubt, is get onto it and create the environment that's going to

119 attract people and build the building

Figure 1. Transcript of full episode 


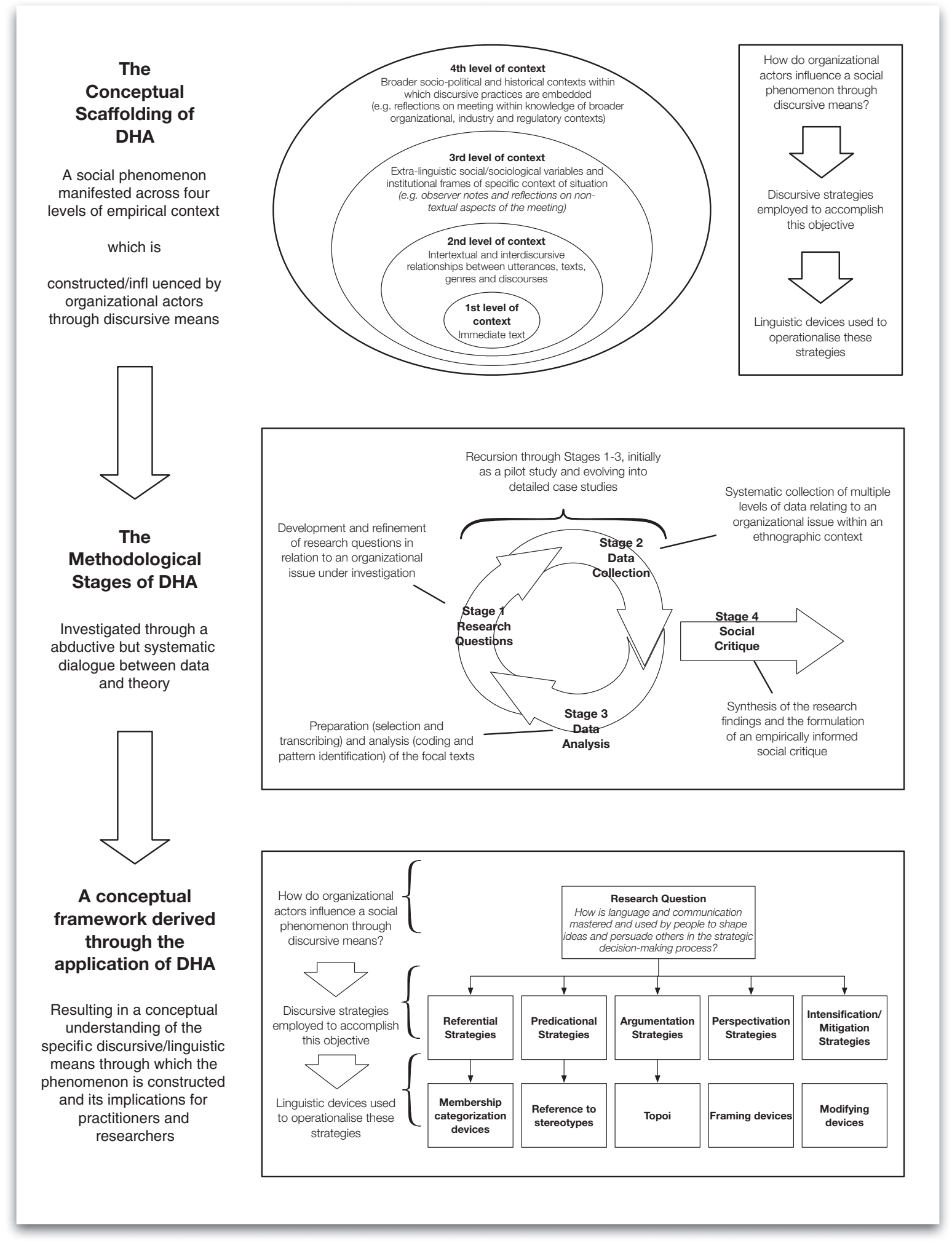

Figure 2. The discourse historical approach

(C) 2011 The Author(s)

British Journal of Management (C) 2011 British Academy of Management. 
1. the immediate text of the communicative event in question (e.g. in this analysis, the transcript of part of a senior management team meeting)

2 . the intertextual and interdiscursive relationship between utterances, texts, genres and discourses (e.g. transcripts of individual interviews with team members, other meetings, meeting minutes and agendas of meetings, powerpoint presentations)

3. the extralinguistic social (e.g. physical gestures, facial expressions, posture) and environmental (e.g. room size and layout) variables and institutional frames (e.g. formal hierarchical structure, informal power relations, institutional imperatives) of a specific 'context of situation' (derived from observer notes and reflections on direct observations of the communicative event)

4. the broader socio-political and historical context which discursive practices are embedded in and related to (e.g. knowledge derived from ethnographic study of the organization and aspects of the broader social and cultural macro-environment that influence the direction and sustainability of the organization).

Understanding the empirical phenomenon as having hierarchical levels of context then allows us to begin to unpack the relationship between the motivations (e.g. underlying agendas, ingrained attitudes and practices) of organizational actors and their actions (i.e. what they say and do). This relationship between intent and action can be understood through the linguistic concepts of discursive strategies and linguistic devices. By use of the term 'strategy' here, the DHA implies a more or less intentional plan of practices (including discursive practices) adopted to achieve a particular goal, a definition which draws on Bourdieu's (1972) conception of the strategies of individuals as a dynamic interaction between habitus, internalized disposition, social structures and a historically determined set of potential actions.

This distinction between strategies and devices is key to making sense of episodes of social interaction, in that intentions of actors are translated into action through discursive strategies, which are operationalized through linguistic devices. This distinction overcomes the tendency to conflate devices and strategies, which can result in an overly mechanical and deterministic view of the dynamics of discursive interaction (e.g. Samra-
Fredericks, 2003). A metaphor, for example, is a linguistic device that can be employed in different types of discursive strategies used by actors to translate their intentions into action, a dynamic that we expand upon later in this paper.

\section{The methodological stages of DHA}

The DHA involves four stages of analysis, illustrated in the middle box of Figure 2, concerning a key organizational issue: the development and refinement of appropriate research questions; the systematic collection of data linked to the research questions; the preparation, analysis and drawing of conclusions from the data; and the formulation of critique and application of the results (Reisigl and Wodak, 2009; Wodak, 2009).

The first stage involves the identification of a social issue of relevance to organization studies. For example, in our own research, we formulated a discourse-related question which concerned our study in DSI: how is language and communication mastered and used by people to shape ideas and persuade others in the decision-making process?

In the second stage, we collected two main types of data to address the question, recording discussion of senior executive meetings over several months and collecting information that helped us understand participants and the context of their operation. This information included interviews with each team member and other stakeholders in depth before and after our observation and recording of their regular all-day monthly meetings. We also collected company documents, including strategic plans, consultants' reports and briefing papers provided to the team in their meetings. Finally, we compiled field notes from our own observations. This ethnographic dimension of data collection is critical to applying the DHA to an organizational context, as it provides the researcher with both the tacit and explicit knowledge to make sense of the three levels of context beyond the immediate text.

Having amassed various types of data in response to the initial research question, the third stage encourages the researcher to be selective about the data they employ, so as to narrow down the research question. We downsized the data by focusing initially on the transcripts of the meet- 
ings of one of the business unit senior management teams that we studied. Guided by our own observations of discourses facing both teams such as recruitment and retention of personnel we narrowed down our research questions to how individuals present their ideas within discussion in meetings and seek to influence decision outcomes, and how their ability to do so is linked to the wider context layers of the situation in which they operate. We began by using excerpts of data for the purposes of conducting a qualitative pilot analysis, similar to that which we present in Figure 1 of this paper. The episode is used to test assumptions and develop analytic categories and hypotheses. Following on from Cooren et al. (2006), we chose a discrete extract that was short and circumscribed in space and time, and not too complex to explain within a paper, and which related to a clearly identifiable objective - in this case the building of a new facility. The relatively discrete nature of our episode is demonstrated through analysis of the entire corpus of our meetings data. ${ }^{2}$

It is clear from this discrete episode that the 'need' for the building was justified and counterjustified interdiscursively, mainly by participants referring to a variety of discourses, but especially those affecting the company's human resources, such as the tight local labour market. 'Discourses' are manifested in different types of 'text' or genres, which we explain further below. In our example, this is best illustrated by the text concerning the production 'numbers' that were needed to justify the building, with some actors implying that the need was clear, whereas others did not feel that this was the case. Such discussion

\footnotetext{
${ }^{2}$ Over a six month period of observation and recording of meetings in DSI, quantitative analysis of the data shows that the terms 'building', 'build' or 'built' were referred to in every one of the six full days of meeting transcripts. However, results show that only in two months was discussion using these terms significant, in months 1 ( $38 \%$ of references) and 3 (47\% of references). Closer qualitative inspection of the two meetings shows that discussion in the first meeting focused on references to the need to construct a particular new building - the one referred to in our chosen episode - whereas in the second meeting most of the discussion came from discussions with construction companies who had made presentations to the team in their meetings. We are therefore confident that the episode of decision-making to which we refer was discrete and was not carried out over time across a number of meetings, like many other topics.
}

tended to be open and fluid from the perspective of participants and researchers. On several occasions, for example, the research team debated whether or not a decision was actually constructed in this episode, or whether the team was simply trying to 'make sense' of a difficult issue.

As in other forms of CDA, the DHA assigns texts to genres (such as the genre of a meeting). Corbett (2006) presents the scholarly history of research on genre, beginning with Aristotle (reproduced 2003) up to literary studies as exemplified by William Hazlitt in his Lectures on the English Poets (1933). Russian Formalists in the 1920s and 1930s (Propp, 1968; and much later, Bakhtin, 1986) already elaborated notions of genre. Bakhtin's early work (1986, p. 60, cited in Corbett, 2006, p. 27) defined genre as each separate utterance, but emphasized that each sphere in which language is used tends to develop its own relatively stable types of these utterances - what he defined as 'speech genres'. Most recently, functional systemic linguistics, sociolinguistic studies on language in the professions, discourse studies, and applied linguistics have also extensively discussed the concept of genre (Renkema, 2004; Wodak, 2008).

Swales (1990) takes situations and their conventions as a starting point, and proposes the concept of 'discourse community' as constitutive for the use and creation of genres. Discourse communities are defined inter alia through a broadly agreed set of common public goals, through mechanisms of intercommunication among their members; through their own genres; through their own lexis; and through a suitable degree of relevant content and discursive expertise (see also Corbett, 2006, p. 29). Hence, each peer-group or sub-group will develop their own goals, their own styles, their own genres and their own values. Such a definition relates well, for example, to scientific communities, their journals, their publication rules, their writing requests, professional lexicon and terminology, and their argumentation devices. Barton (1994) elaborates Swales' approach and integrates the notion of discourse communities into literacy studies. In CDA more generally, a 'genre' may be characterized as 'a socially ratified way of using language in connection with a particular type of social activity' (Fairclough, 1995, p. 14).

The DHA moreover considers intertextual and interdiscursive relationships between utterances, 
texts, genres and discourses, as well as extralinguistic social/sociological variables, the history of an organization or institution, and situational frames. Hence, following on from the heuristic of four levels of context (Figure 2), we also drew off other genres of data (e.g. our reflections, interviews and field notes) and were able to surface connections between different discussions (e.g. a discourse over the new building as opposed to the discourse over employee recruitment and retention) through, for instance, what we had heard from interviews with individuals - a quite different genre of data. The DHA also explores how discourses, genres and texts change in relation to wider socio-political events, by relating texts to other texts in the past and present, a process called 'intertextuality'. As defined by Wodak (2008), intertextuality refers to the fact that all texts are linked to other texts, both in the past and in the present, and provides the main rationale for using the DHA as a methodology, because understanding it allows the researcher to deconstruct the immediate and long-term history of topics, genres and discussions. Such links can be established in different ways: through continued reference to a topic or main actors; through reference to the same events; or by the transfer of the main arguments from one text into the next. This process is also labelled 'recontextualization' (see Bernstein, 1990). By taking an argument and restating it in a new context, we first observe the process of decontextualization, and then, when the respective element is implemented in a new context, of recontextualization. The element then acquires a new meaning, because meanings are formed in use (see Wittgenstein, 2001). 'Interdiscursivity', in contrast, indicates that discourses are linked to each other in various ways. If we define discourse as primarily topic related, i.e. a discourse on X, then a discourse on un/employment often refers, for example, to topics or subtopics of other discourses, such as gender or racism: arguments on systematically lower salaries for women or migrants might be included in discourses on employment. Consequently, the DHA emphasizes why discourses are open and hybrid, with new subtopics frequently being created at many points.

In sum, we can observe a move from inherent textual characteristics to a more functional approach to, finally, an approach focused on social practices, conventions, rules and norms governing certain sets or groups of speakers and hearers (viewers/listeners). Both processes tell the researcher a lot about how an organizational phenomenon occurs discursively (such as the making of a decision), and show how issues can acquire new meanings as understanding of them is framed or reframed (Wodak, 2000, 2008; Wodak and Fairclough, 2010). Hence, this approach can reveal in practical terms how intertextuality is applied in lines 42-50 in Figure 1 (also the extract used in the Introduction to this paper), when the Chief Operating Officer (COO, Bradley) and Managing Director (MD, Mike) draft other texts into the debate, including the geographical distribution of their facilities in different cities

In the fourth and final stage, DHA uses insights generated from the qualitative pilot and detailed case studies to construct a critique of the theoretical issue under investigation. In this particular case, we have employed only one pilot episode and detailed study at each level of context, as an illustration of the first cycle of analysis. While we can begin to draw insights from this initial pilot case study (as we do in the discussion section below), we draw attention to the fact that recursive analysis of successive episodes is characteristic of the DHA as a methodology for retroductive theory building, a process that uses insights from field analysis constantly to challenge existing theory. Central to the DHA is the application of the analytical results that stem from the critique. As with all forms of CDA, the application of the results can be made accessible to wider audiences and, in this case, management practitioners, so that they can be used to affect practical change by better understanding and influencing the talk in meetings. This retroductively derived conceptual framework is explained in further detail below and also illustrated in the lower box in Figure 2.

Beginning with the research question: 'How is language and communication mastered and used by people to shape ideas and persuade others in the strategic decision-making process?', we proceeded to investigate this issue within the context of a senior management team in a business unit of DSI. Following the four-stage recursive process described above, and informed by the conceptual scaffolding of DHA, we further refined this research question into more detailed questions concerning how language is used to influence the decision-making process. 
Table 2. A list of topoi of argumentation

\begin{tabular}{ll}
\hline Topos of Authority & An action is legitimate if mandated by someone in authority \\
Topos of Burden & A problem needs to be acted on if a person or institution is burdened by it \\
Topos of Definition & A person / object with certain attributes of X should be classified and treated as X \\
Topos of History & An action should / should not be performed if history teaches us that it has consequences \\
Topos of Justice / Equity & A person should be treated in a certain way if equal in other respects \\
Topos of Numbers & Sufficient numerical evidence means an action should / should not be performed \\
Topos of Reality & A particular action needs to be performed given the way reality as it is \\
Topos of Threat & An action should be performed if specific dangers are identified \\
Topos of Urgency & A decision / action needs to be made if an event requires such a response \\
\hline
\end{tabular}

Although there are many linguistic and rhetorical means by which organizational actors use language in a goal-directed manner, we focused specifically on five simple heuristic questions related to how these actors mobilized representations of themselves to influence the outcome of the discussion: How are persons/groups relevant to a strategic issue named and referred to linguistically? What traits, qualities and characteristics are attributed to them? What arguments and argumentation schemes do organizational actors use to convince others to support/oppose an issue? From what perspective or point of view are these previous three points expressed? Finally, how is the strength of these arguments intensified or mitigated?

Corresponding to these questions, which are all related to positive self-presentation and negative other-presentation, we identified five types of discursive strategies used commonly in the discussion of strategic issues:

1. Social actors are named and referred to in order to mobilize support for an issue through nominational strategies operationalized through linguistic devices (e.g. tropes, metaphors, metonymies and synechdoches), often for the creation of 'ingroups' and 'outgroups'. For example, Mike the MD and others repeatedly refers to employees in the possessive sense 'we've got ... people' (e.g. lines 79 and 80). In doing so, these employees are portrayed as owned ('our people') rather than merely as 'human resources'. This is in contrast with the observations of another business unit within DSI, where the directors used the more impersonal term 'employees' as the need for layoffs and transfers became imminent.

2. Having been constructed or identified, social actors are provided with predications which portray them linguistically in a positive or negative light. The purpose of these predicational strategies is to establish the perception of these social actors as an 'opportunity' to be engaged with or a 'threat' to be marginalized by the group. For instance, the COO Bradley comments that, 'We've got people spread all over the fucking place in really substandard operating environments' (lines 110-112). In doing so, he implies that current conditions are unfair to 'our people', thereby portraying these actors positively.

3. Argumentation strategies are employed to establish the logic of the argument by outlining how the issue should be dealt with. A good example is when Bradley argues that, if you take the decision that you're in a sustainable business', DSI must 'create the environment that's going to attract people and build the building' (lines 118-119). In this case, he employs a particular 'topos' (warrant leading to a conclusion), the topos of threat - that unless the new building is built, DSI will continue to have problems recruiting and retaining good employees. These topoi of argumentation are condensed versions of fully elaborated argumentation structures (Toulmin, 1958) in which warrants appear without evidence as backing (in the short form 'if $p$, then q'). These condensed arguments are dependent on the common sense and context-sensitive logic of speakers and listeners to be understandable. An annotated list of topoi is shown in Table 2 (see Kienpointner, 1992; Kwon, Clarke and Wodak, 2009).

4. Arguments are framed to reinforce the speaker's point of view through perspectivation strategies in which linguistic devices such as direct/ indirect quotations or direct expressions of opinions are employed to align the issue with them, or a certain field of action, or a certain discourse topic. An example of this can be seen 
when MD Mike interrupts the current topic of discussion by interjecting with the question, 'What would be the quality of the accommodation if you decided to ... ?' (lines 77-78). Here Mike uses the question to reframe the discussion about the new building as a decision that should not be solely based on quantitative financial criteria, but also qualitative criteria such as accommodation quality.

5. Intensifying and mitigating strategies are used to modify the epistemic status of a proposition in order to position it higher/lower in the organizational agenda and thus promote or relegate its relative claim on organizational attention and resources. An example of this occurs when COO Bradley argues that there is 'a huge challenge around the business in terms of retention' which will get worse 'without a half decent working environment' (lines 112115). Here Bradley is using intensification to elevate the strategic importance of the issue to the overall organization. Used in combination with an argumentation strategy (topos of threat), Bradley succeeds in elevating the decision over the new building into an issue of strategic importance which has significant implications for the long-term viability of the organization.

In sum, therefore, the DHA has two novel features that distinguish it from other forms of CDA (Figure 2): four 'levels of context' as heuristics within which discursive practices, strategies and texts can be located; and the range of 'discursive strategies' and related 'linguistic means' used by participants to achieve their aims via positive selfpresentation of their position in relation to a strategic issue. As in ethnography, the context layers that are characteristic of DHA enable researchers to deconstruct meanings related to contextual levels and frames that impinge on the unique realized texts and utterances, but as we show, it does so in a more structured way.

\section{Discussion}

To illustrate this conceptual framework further, we now draw on an excerpt from the text of the same decision-making episode in more detail to show how, at each stage of the discussion, these four levels of analysis and discursive strategies are brought to bear (see Figure 3) to develop new insights.

Figure 3 parsimoniously summarizes the insights from our DHA, and we ask the reader to pause at this point and to work systematically down and across the episode. This step-by-step analysis is salient because it interprets the different results within the social, historical and political contexts of the discourse under consideration, summarizing the insights generated at different levels of context. To bring the analysis of this narrative to life and give the reader an idea of what insights the DHA facilitates, below we offer an illustration from the first half of the episode (cf. lines 1-60 and across Figure 3 at each level of context). For reasons of space, we restrict this to the analysis of the behaviour and motives of a single individual - Will, the Director of the Osprey Programme.

Analysing this excerpt at the first level of context, this episode starts with an interchange between Ted (Director of Manufacturing) and Will, both of whom use Referencing as a salient discursive strategy (lines 1-13). Here, they give their 'views' and 'forecasts', but neither has tangible support and instead uses verbs like 'we've taken ...' 'and 'I think it's ... so what we're doing ...', referring to individuals who have produced the forecasts as a means to provide an endorsement for their own respective views. Implicit to what they are doing here is to encourage team members to join with them in their respective views. The MD Mike responds by questioning Will's bottom-up approach to head count, employing a Mitigation discursive strategy to ameliorate his criticism by saying 'I don't mind ...' but then uses Intensification by drawing attention to the acute difference between their views by saying to Will via a speech-act of command 'you're going to have to ....' Greg (the Director of Contracts) then emphasizes the difference between their own and Will's view by saying 'you're never going to ...' (lines 21-22), thus distancing himself from Will's approach. Bradley then weighs in to support Mike's position using Referencing along with an argument based on the topos of reality, 'we've got what we've got ... we'd better cater for that ...' (lines 43-44). Bradley reinforces the tension between the views and draws the episode to an end by using a profanity. The picture revealed by analysis of this first 
level of context (i.e. recordings and transcriptions of this meeting episode) is one of a spontaneous and earnest discussion about a decision over whether or not to build Building B.

At the second level of context (inter-textual and inter-discursive relationships), a rather different interpretation emerges. In a subsequent meeting eight months later, Adam (HR Director) revealed that the decision to build Building B was, in fact, staged:

To be fair, my view of that, my synopsis of that discussion, I don't think Will represented that fair, I don't think I represented that fair, I think we were given a mandate by Jack, which was to 'go and build Building B' and we took that as our mantra. You are right, we did do the sums around leasing property around the CBD, and you've stuck that against the cost of Building B. You are right, Building B was a better long-term investment. And we made that decision. But I don't think we really thought through Comms, shiftwork, and some of these other things that make us competitive.

What followed from this comment was a discussion in which Adam, Will and Greg began to air their misgivings about the previous decision and question whether Building B was really the best option for expanding DSI's facilities. At this meeting, eight months after the initial decision, consensus over Building B disintegrated. We also know from interviews with Adam and Bradley that Will's bonuses are directly linked to the meeting of performance targets set for the Osprey programme. Furthermore, actions that were in the broad interests of DSI, such as making larger and more realistic headcount projections to support the business case for Building B, were actually in conflict with his narrower personal interests. Therefore, a further interpretation of this excerpt now emerges. With the exception of Will, the other team members (Ted, Mike, Greg and Bradley) were apparently 'going through the motions' of agreeing to build Building B. Read differently, therefore, this excerpt can be interpreted not so much as a spontaneous and earnest discussion, but rather a staged motion to ratify a decision already made by Jack, the DSI Group CEO. At this point we can speculate that Will's failure to 'go along' with the staging was perhaps an attempt at resisting the decision, a sentiment aired at a subsequent meeting (Wodak, Kwon and Clarke, 2011).
Outside the linguistic interactions, the third level of context examines the social/sociological and institutional context. As two of the authors of this paper were observers of this meeting, we know that it took place in a corporate entertainment box which overlooked a major international cricket ground. At the time, we noted as researchers how the combination of the venue, coupled with fine weather, participants' jocular mood, and the MDs Northern Irish accent and manner provided a sense of levity to the meeting, such that the tone of the discussion was much less divisive and more relaxed than a pure textual analysis alone might suggest. Furthermore, Will had joined the 'awayday' meeting late, having come directly from the airport from a long international flight. The team stood up and applauded him when he entered the room, given his success in winning the Osprey contract, a project that promised to provide the majority of DSI Australia's revenues over the next few years. It was evident, however, through his behaviour that Will was jet-lagged and that this had the effect of disorienting his performance, so that he came over as 'hedging' or softening/backing-up each point he made. Compared with our observations of Will in subsequent meetings, we noted later that his hedging in this instance was very uncharacteristic of his personal style. Thus, we know now that much of Will's behaviour was caused by fatigue rather than motivated by conscious resistance.

The fourth level of context encourages placing the main discussion text in relation to the broader socio-political and historical contexts in which they were embedded. For example, from our attendance at several previous meetings, interviews with individual team members, reading company documents, industry documents, and discussions with other personnel in the company but outside the senior management team, it had become clear that a key imperative to building the new building was the intense competition facing the company over a long period within the Australian state in which they were based. We know from these broader reference points that defence and mining are the two primary industries in the state, and that there had been continued demand for labour and 'poaching' from other firms. This manifested itself as a dilemma: whether to invest in a new facility in the tight regional labour market, or to spread 


\section{1st level of context} Immediate language



Figure 3. Detailed analysis of excerpts from full episodes

(C) 2011 The Author(s)

British Journal of Management (C) 2011 British Academy of Management. 


\section{2nd level of context Inter-textual and inter-discursive relationships}

We know from interviewing Will beforehand that he felt "It's not all in the numbers" and that he felt that the Osprey programme alone would not be

(1) adequate to support the case for the

new building. Rather a new building would make DSI a more inspiring place for engineers to work. Other discourses are also being brought into play, with Ted referring to demands of particular projects to add weight, and Will stressing making the location physically more appealing to attract engineers their to work

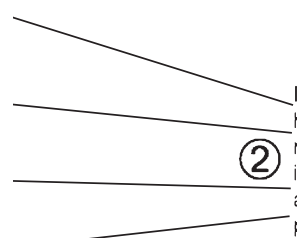

In our interview with the MD Mike, he had stressed the tendency of his senio management team to get bogged down in operational concerns, explaining his apparent impatience we observed at this point in the meeting.

In the organization this discourse of financial control was evident as a stretching process of going beyond the IP and was referred to as 'tasking' or 'stretch targets'. In individual interviews with the HR Director, Adam, and the $\mathrm{COO}$, Bradley, both had stressed the importance put on 'stretch' targets in the process of giving people performance

(3) bonuses. Understanding this helps the analyst to appreciate why Will was reluctant to be realistic about future business prospects attached to his Osprey programme, as it would have reduced the chance of him hitting stretch targets

\section{3rd level of context Extra-linguistic social/ sociological and institutional context}

We know from our own field notes that Will joined the 'awayday' meeting late, coming directly from the airport from an international flight. The team applauded him for winning the Osprey contract when he entered the room, but it was evident that his jet-lag made his performance disoriented, and was reflected in his constant 'hedging' of the points he made.

From over 8 months of ethnography in the UK and Australia, we became aware that Financial Control was a strong and powerful practice in DSI. The main reason for this was that DSI had taken over another global defence company with strong financial practices. Following the takeover, the majority of Financial Directors moved into prominent position in DSI businesses. This included DSI's Finance Director and MD Mlke's boss (Jack), the Group CEO. The implication of this is that financial controls are a dominant discourse within the DSI Group and that the 'bottom-up' approach is a 'default' means of justifying decisions within the organization. Mike's frustration is in part due to the fact that the 'bottom-up' approach will not lead to the conclusion that he has been mandated to 'stage'.

I

Further light is reflected on this interaction and Will's hesitation to endorse the need for a new building with his new Osprey contract through exit interviews conducted at the end of our research period. Several members of the team individually told us of Will's reluctance to share information and resources with other parts of the business. They explained this with reference to DSI's performance compensation system in the institution, which rewarded based on achieving certain targets. In Will's case this was based on the performance of the Osprey programme alone. Thus any actions that were broadly supportive of the business as a whole, such as increasing his headcount projections so as to justify the Building $B$, were not necessarily in his personal interests.

In over 6 months observing the MD, we found he frequently used humour in meetings to mitigate criticisms he was making or to make cutting remarks at individuals. At a personal level, he also confided in informal meetings with us about his "lack of engineering

knowledge" as a leader of a major engineering company (he was a trained lawyer). At this point in the episode we see an example of his humour, stating in a broad northern Irish brogue that what the $\mathrm{COO}$ was saying was what he had been saying for years.

Figure 3. Continued

\section{4th level of context Broader socio-political and} historical context

From observations of several previous meetings, interviews with individual team members, company documents, industry documents, and other personnel, it was clear the imperative to build the new building was the intense competition facing the company over a long period. Defence and Mining were primary industries in the Australian state in which the site is based, and there had been continued demand for labour and 'poaching'. This broader debate manifested itself in the dilemma of the decision: do they invest in a new building in the tight regional market, or spread risk by building elsewhere in another state? The example reflects Australia's dilemma chronicled by leading historians - a 'tyranny of distance' both from interstate internal markets as well international ones.

The upshot of these two strands of argument is that there was major contextual pressure being exerted on the organization to treat the workforce well in a historically highly competitive regional abour market. In DSI, where financial culture was paramount, Will was being put under pressure to provide the quantitative evidence to support the rationale to build Building $\mathrm{B}$.

(C) 2011 The Author(s)

British Journal of Management (C) 2011 British Academy of Management. 
risk by building elsewhere in another state. Thus, the earlier attempt to stage the decision in this excerpt and the subsequent disintegration of the consensus to build were both borne out of conflicting perspectives on how to best deal with these broader institutional forces. Will's own fumbling acquiescence in the excerpt and his resistance in the subsequent meeting can be seen as a microcosm of these broader forces.

\section{Conclusion}

The four levels of context and details of our illustration shown in Figure 3 are akin to an impressionist painting whose overall meaning only begins to be resolved when adequate 'distance' is placed between the painting and the viewer, with each level helping the researcher to grasp cues essential to a more robust interpretation of this strategy meeting.

Rather than the outcome of the discussion in our episode being due to any single factor, the systematic application of the DHA shows just how the final outcome from the discussion was influenced not only by the logic of argumentation and discursive skills of the participants, but also by powerful actors imposing their authority, the situation of the meeting (such as conditions within the room and the nature of the venue) and personal factors (such as individuals' physical condition and shifts in their standing over time), as well as the structural and cultural constraints of sociopolitical and historical conditions. In other words, the DHA illustrates just how strategic discussion is constructed and recontextualized through the episode, rather than simply being 'made' rationally at the end. It demonstrates the value of a disciplined and recursive analysis of discussion surrounding organizational phenomena of the four levels of context.

The primary contribution of the paper, therefore, is to provide an approach through which the context of talk involved in meetings relating to strategy and strategic practice can be systematically and explicitly analysed. We believe that the DHA will help to address the call for more empirical studies that adequately bridge microand macro-levels of analysis by providing a structured approach that enables such research to be conducted (Jarzabkowski and Spee, 2009; Jarzabkowski, Balogun and Seidl, 2007; Johnson,
Melin and Whittington, 2003; Whittington, 2006). The DHA's methodological contribution to strategy research is to create a 'methodological bridge' between (a) the growing body of empirical work on strategy meetings (e.g. Bürgi et al., 2005; Hendry and Seidl, 2003; Heracleous and Jacobs, 2008; Hodgkinson and Wright, 2002; Jarzabkowski and Seidl, 2008; Johnson et al., 2010; Maitlis, 2005) which focuses on the relationship between organization outcomes and the activities of managers but is removed from managers' real-time discussions; and (b) the research on workplace discourse and communications (Samra-Fredericks, 2005, 2003; e.g. BargielaChiappini and Harris, 1997, Holmes and Stubbe, 2003) which examines the naturally occurring talk of managers in meetings in substantial detail, but tends to leave the relationship between local talk and broader organizational outcomes relatively unexplored. The DHA provides a methodological framework to make such linkages.

The paper also makes a secondary methodological contribution to the source domain of linguistics from which it is developed by (i) extracting the method from the original research question within the DHA approach; and (ii) adapting it to accommodate a substantial ethnographic component necessary to study teams of managers in real-time discussion. Hence, we provide a CDA approach that other linguistic scholars can use to study a range of organizational phenomena at the level of naturally occurring talk.

In addition to these methodological benefits of the DHA to researchers of strategy, we intimated at the beginning of this paper that we would also highlight the benefits of the approach to practitioners. While this is not the central aim of this paper, we would like to draw the attention of strategy scholars to two corollaries of these methodological contributions, for strategy practitioners. First, it is our experience of using episodes of discussion from meetings in workshops with senior executives, like the episode used here, that the four levels of context that characterize the DHA, help participants to 'unpack' what they know intuitively is going on: it helps them 'get it' more incisively. Executives are able to use the four levels as 'lenses' on the episode, so that they can see not only how individual actors deploy discursive skills, but also how they do this with subtlety (or blatantly in some cases) to impose 
their authority, exerting power through the exercise of discussion. By drawing attention to the influence of these skills, practitioners in workshop situations immediately become aware of the effect of both linguistic means (e.g. using a metaphor) and pragmatic means (e.g. banging the table), and thus the value of practising these approaches so that they become more discursively skilled, while also being able to detect the use of such discursive means by other colleagues, so that they can respond accordingly. Second, because the analyst is able to reveal the interconnections between what is going on in the text and the broader context of discussion, such as the political climate within the organization, or the history of specific agenda, or the local industry dynamics, or the physical demeanour of a participant at any given point in time, we have found that executives are able to appreciate better where, why and when, and the extent to which, their discursive skills 'make a difference'. The DHA therefore helps strategy practitioners to develop a much richer understanding of how something as important as a decision is not simply 'made', but rather constructed through an interactive process between actors who are more or less discursively skilled.

Overall, we believe that the paper demonstrates that the DHA to CDA overcomes fundamental methodological problems by providing researchers with a nuanced and systematic approach to analysing the text and context of talk in strategy meetings. In doing so, the approach outlined in this paper allows us to isolate four 'levels of context' as heuristics within which discursive practices, strategies and texts can be located. By systematizing and making explicit the levels of contextual analysis that are implicit in other approaches to discourse analysis and organizational ethnography, and using an episode of discussion from a strategy meeting to illustrate the approach, we provide strategy researchers with the means to obtain and analyse the explicit and tacit knowledge they need to make sense of, and develop new insights into, the talk of strategists. In doing so, we provide researchers with the practical and theoretical tools to build linkages retroductively between (i) the macro-level organizational and extraorganizational contextual factors; (ii) the microlevel activities of strategists; and (iii) broader organizational outcomes.

\section{References}

Aristotle (2003). Poetics. London: Penguin.

Baker, P., R. Wodak, C. Gabrielatos, M. Khrosravinik, M. Krzyzanowski and T. McEnery (2008). 'A useful methodological synergy? Combining critical discourse analysis and corpus linguistics to examine discourses of refugees and asylum seekers in the UK', Discourse and Society, 19, pp. 273-306.

Bakhtin, M. (1986). Speech Genres and Other Late Essays. Austin, TX: University of Texas Press.

Bargiela-Chiappini, F. and S. Harris (1997). Managing Language: The Discourse of Corporate Meetings. Amsterdam: John Benjamins.

Barton, D. (1994). Literacy: An Introduction to the Ecology of Written Language. Oxford: Blackwell.

Bernstein, B. (1990). The Structuring of Pedagogic Discourse. London: Routledge.

Bourdieu, P. (1972). Outline of a Theory of Practice. Cambridge: Cambridge University Press.

Bürgi, P. T., C. D. Jacobs and J. Roos (2005). 'From metaphor to practice: in the crafting of strategy', Journal of Management Inquiry, 14, pp. 78-94.

Chilton, P. (2010). 'Critical discourse analysis'. In P. C. Hogan (ed.), The Cambridge Encyclopedia of the Language Sciences. Cambridge: Cambridge University Press.

Chilton, P., H. Tian and R. Wodak (2010). 'Reflections on discourse and critique in China and the West', Journal of Language and Politics, 9, pp. 489-507.

Cooren, F. (ed.). (2007). Interacting and Organizing: Analyses of a Management Meeting. Mahwah, NJ: Lawrence Erlbaum.

Cooren, F., F. Thomson, D. Canestraro and T. Bodor (2006). 'From agency to structure: analysis of an episode in a facilitation process', Human Relations, 59, pp. 533-565.

Corbett, J. B. (2006). 'Genre and genre analysis'. In K. Brown (ed.), Encyclopaedia of Language and Linguistics, pp. 26-32. Amsterdam: Elsevier.

Fairclough, N. (1995). Critical Discourse Analysis. Boston, MA: Addison Wesley.

Foucault, M. (1972). The Archeology of Knowledge. London: Routledge.

Hazlitt, W. (1933). Lectures on the English Poets. Oxford: Oxford University Press.

Hellgren, B., J. Löwstedt, L. Puttonen, J. Tienari, E. Vaara and A. Werr (2002). 'How issues become (re)constructed in the media: discursive practices in the AstraZeneca merger', British Journal of Management, 13, pp. 123-140.

Hendry, J. and D. Seidl (2003). 'The structure and significance of strategic episodes: social systems theory and the routine practices of strategic change', Journal of Management Studies, 40, pp. 175-196.

Heracleous, L. and M. Barrett (2001). 'Organizational change as discourse: communicative actions and deep structures in the context of information technology implementation', Academy of Management Journal, 44, pp. 755-778.

Heracleous, L. and C. D. Jacobs (2008). 'Understanding organizations through embodied metaphors', Organization Studies, 29, pp. 45-78.

Hodgkinson, G. P. and G. Wright (2002). 'Confronting strategic inertia in a top management team: learning from failure', Organization Studies, 23, pp. 949-977. 
Holmes, J. and M. Stubbe (2003). Power and Politeness in the Workplace. A Sociolinguistic Analysis of Talk at Work. London: Longman.

Jarzabkowski, P. and D. Seidl (2008). 'The role of meetings in the social practice of strategy', Organization Studies, 29, pp. 1391-1426.

Jarzabkowski, P. and A. P. Spee (2009). 'Strategy-as-practice: a review and future directions for the field', International Journal of Management Reviews, 11, pp. 69-95.

Jarzabkowski, P., J. Balogun and D. Seidl (2007). 'Strategizing: the challenges of a practice perspective', Human Relations, $\mathbf{6 0}$, pp. 5-27.

Johnson, G., L. Melin and R. Whittington (2003). 'Micro strategy and strategizing: toward an activity-based view', Journal of Managment Studies, 40, pp. 3-22.

Johnson, G., S. Prashantham, S. W. Floyd and N. Bourque (2010). 'The ritualization of strategy workshops', Organization Studies, 31, pp. 1-30.

Keenoy, T. and C. Oswick (2003). 'Organizing textscapes', Organization Studies, 25, pp. 135-142.

Kienpointner, R. (1992). Alltagslogik. Struktur und Funktion von Argumentationsmustern. Stuttgart-Bad Cannstatt: Frommann-Holzboog.

Knights, D. and G. Morgan (1995). 'Strategy under the microscope: strategic management and IT in financial services', Journal of Management Studies, 32, pp. 191-214.

Kwon, W., I. Clarke and R. Wodak (2009). 'Organizational decision-making, discourse, and power: integrating across contexts and scales', Discourse and Communication, 3, pp. 273-302.

Laine, P.-M. and E. Vaara (2007). 'Struggling over subjectivity: a discursive analysis of strategic development in an engineering group', Human Relations, 60, pp. 29-58.

Lalouschek, J., F. Menz and R. Wodak (1990). Alltag in der Ambulanz. Tübingen: Niemeyer.

Linde, C. (2008). Working the Past: Narrative and Institutional Memory. Oxford: Oxford University Press.

Maitlis, S. (2005). 'The social processes of organizational sensemaking', Academy of Management Journal, 48, pp. $21-49$.

Mantere, S. and E. Vaara (2008). 'On the problem of participation in strategy: a critical discursive perspective', Organization Science, 19, pp. 341-358.

Mumby, D. K. and R. P. Clair (1997). 'Organizational discourse. In T. A. Van Dijk (ed.), Discourse Studies, Vol. 2: Discourse as Social Interaction, pp. 181-205. London: Sage.

Phillips, N., G. Sewell and S. Jaynes (2008). 'Applying critical discourse analysis in strategic management research', Organizational Research Methods, 11, pp. 770-789.

Potter, J. and M. Wetherell (1987). Discourse and Social Psychology: Beyond Attitudes and Behaviour. London: Sage.

Propp, V. (1968). Morphology of the Folktale. Austin, TX: University of Texas Press.

Reisigl, M. and R. Wodak (2001). Discourse and Discrimination: Rhetorics of Racism and Antisemitism. London: Routledge.

Reisigl, M. and R. Wodak (2009). 'The discourse-historical approach'. In R. Wodak and M. Meyer (eds), Methods of $C D A$, 2nd revised edn, pp. 87-121. London: Sage.
Renkema, J. (2004). Introduction to Discourse Studies. Philadelphia, PA: John Benjamins.

Samra-Fredericks, D. (2003). 'Strategizing as lived experience and strategists' everyday efforts to shape strategic direction', Journal of Management Studies, 40, pp. 141-174.

Samra-Fredericks, D. (2005). 'Strategic practice, "discourse" and the everyday interactional constitution of "power effects", Organization, 12, pp. 803-841.

Stohl, C. (2007). 'Bringing the outside in: a contextual analysis'. In F. Cooren (ed.), Interacting and Organizing: Analyses of a Management Meeting, pp. 185-198. Mahwah, NJ: Lawrence Erlbaum.

Swales, J. M. (1990). English in Academic and Research Settings. Cambridge: Cambridge University Press.

Toulmin, S. E. (1958). The Uses of Argument. Cambridge: Cambridge University Press.

Van Dijk, T. A. (2008). Discourse and Context: A Sociocognitive Approach. Cambridge: Cambridge University Press.

Whittington, R. (1996). 'Strategy as practice', Long Range Planning, 29, pp. 731-735.

Whittington, R. (2006). 'Completing the practice turn in strategy research', Organization Studies, 25, pp. 613-634.

Wittgenstein, L. (2001). Philosophical Investigations. Oxford: Blackwell.

Wodak, R. (1986). Language Behavior in Therapy Groups. Los Angeles, CA: University of California Press.

Wodak, R. (1996). Disorders of Discourse. London: Longman.

Wodak, R. (2000). 'Recontextualization and the transformation of meanings: a critical discourse analysis of decision making in EU-meetings about employment policies'. In S. Sarangi and M. Coulthard (eds), Discourse and Social Life, pp. 185206. Harlow: Pearson Education.

Wodak, R. (2001). 'The discourse-historical approach'. In R. Wodak and M. Meyer (eds), Methods of Critical Discourse Analysis, pp. 63-95. London: Sage.

Wodak, R. (2008). 'Introduction: discourse studies - important concepts and terms'. In R. Wodak and M. Krzyzanowski (eds), Qualitative Discourse Analysis in the Social Sciences, pp. 1-29. Basingstoke: Palgrave Macmillan.

Wodak, R. (2011). The Discourse of Politics in Action: 'Politics as Usual', 2nd revised edn, Basingstoke: Palgrave Macmillan.

Wodak, R. (2009). 'The semiotics of racism - a critical discourse-historical analysis'. In J. Renkema (ed.), Discourse of Course, pp. 311-326. Amsterdam: John Benjamins.

Wodak, R. and N. Fairclough (2010). 'Recontextualising the Bologna Declaration: the Austrian and Romanian case', Critical Discourse Studies, 7, pp. 19-40.

Wodak, R. and M. Meyer (2009). 'Critical discourse analysis: history, agenda, theory and methodology'. In R. Wodak and M. Meyer (eds), Methods of Critical Discourse Analysis, 2nd revised edn, pp. 1-33. London: Sage.

Wodak, R. and G. Weiss (2003). " "We are different than the Americans and the Japanese!": a critical discourse analysis of decision-making in European Union meetings about employment policies'. In E. Weigand and M. Dascal (eds), Negotiation and Power in Dialogic Interaction, pp. 51-70. Amsterdam: John Benjamins.

Wodak, R., W. Kwon and I. Clarke (2011). " "Getting people on board" ': discursive leadership for consensus building in team meetings', Discourse and Society, 22, forthoming. 
Ian Clarke is Chair in Strategic Management and Marketing, and Director of Newcastle University Business School. His research interests focus on management team decision-making, discourse and sensemaking. His is a Senior Fellow of the UK Advanced Institute of Management Research (AIM) and has previously held chairs in UK business and management schools, including Lancaster and Durham. He is an Academician of Academy of Social Sciences (AcSS). Prior to rejoining academe, he was a strategic advisor to Tesco PLC.

Winston Kwon is Lecturer at the Centre for Strategic Management in Lancaster University Management School. His research interests concern the study of decision-making processes within management teams and strategic change initiatives within complex organizations. Prior to returning to academia, he has worked in a number of finance and strategy positions with firms in the technology and consumer sectors. See http://www.lums.lancs.ac.uk/strategy/profiles/winston-kwon/ for current research projects.

Ruth Wodak is Distinguished Professor of Discourse Studies at Lancaster University and has remained affiliated as Full Professor of Applied Linguistics to the University of Vienna, with visiting professorships at Uppsala, Stanford, Minnesota and Georgetown University. She was awarded the Wittgenstein Prize for Elite Researchers in 1996 and an Honorary Doctorate from Örebro University in 2010. Her research focuses on: discourse analysis; language and/in politics; identity politics and politics of the past; prejudice and discrimination; and ethnographic methods of linguistic field work. See http://www.ling.lancs.ac.uk/profiles/265/ for ongoing projects. 